\title{
War and the Worlds and the Promise of Social Media Tools
}

\section{Badreya Al-Jenaibi*}

Mass Communication Department, UAE University, UAE

\begin{abstract}
As a result of many years of repressive dictatorships, the people of Middle East and North Africa (MENA) rebelled to bet their claim to democracy. The political uprisings have been commonly referred to as Arab Spring. In light of the uprisings, which started in Tunisia on December 18, 2010, the World Wide Web and its tools of social media were identified as helpful in aiding the uprisings. This study will focus on the role of the social networks such as Facebook, YouTube, Twitter, and weblogs in raising the Arab discourse and voice in the revolutions in four countries in MENA: Tunisia, Libya, Egypt and Syria which were extensively revealed to the public and followed by the global community. It will closely examine the extent to which activists in the three countries used social media for organizing and creating awareness of political mobilization, and the role-played by the social media tools in the United Arab Emirates. Also discussed is how often the inhabitants of the United Arab Emirates use traditional and social media tools. The study will use well-known theories of communication. The aim is to place the use of social media tools inside a broader background of communication. They are theories, which were devolved long prior to the advent of social media. The theories will also be used to explain the manner, in which inherent aspects of social media networks, which made them attractive to activists, and protesters in the three countries. The study used a multi-method approach, combining survey data from surveys with qualitative data from interviews. Surveys were distributed to 600 people. 454 surveys were received back. For the qualitative part, 27 employees from various media organizations in the United Arab Emirates were interviewed. Data were analyzed using two main component analyses: categorization and descriptive statistics (median, correlation, one-way ANOVA and displays). The study found that after learning Egypt, Libyan, Tunisian and Libyan revolutions, most of the respondents used newspaper, television, radio, Facebook, Twitter, blogs, word-of-mouth, e-mail and mobile devices to spread or share this news.
\end{abstract}

Keywords: MENA countries; Arab Spring; Social media; Social media tools; Old media; Old media sources

\section{Introduction}

The Arab Spring can be referred to as a series of revolutionary revolutions in MENA region. The revolutions have encouraged an increasing debate concerning the role played by the social media networks as a tool for political mobilization towards two main issues: pro-democracy movements and regime change [1]. Several political experts, journalists among other experts have embraced social networks as an indisputable force; they claim, "Democracy is simply a tweet away." Wael Ghonim once said: "If you desire to free a particular society, just give them the World Wide Web" [2]. Note that Ghonim is the Egyptian Google executive. Many times, the World Wide Web has been regarded as a useful weapon for weak persons who have used it to revolt against authoritarian leaders. The result, according to New York Times columnist Nicholas Kristof, is "quintessential Twentyfirst Century conflict." The conflict pits "government gangsters firing bullets on one side. On the other side are young demonstrators; they are firing 'tweets'" [3].

Even prior to the Arab Spring which resulted to civil wars in Syria (the war is going on) among other countries in MENA, the uprisings in Iran and Moldova were considered as "Twitter revolutions" [4]. It is a phrase the global media has embraced. In fact, the phrase leads to an impression of a young tech-savvy generation [5]. Most telling perhaps is that this generation is ousting the old generation. Unsurprisingly, this is not the first time in which a technological innovation was used a weapon for change [6]. The advent of printing press by Gutenberg six centuries ago led to the Renaissance; it played an important role in the weakening of power of the medieval church; and later, the printing press led to the Reformation and Scientific Revolution [7]. Nonetheless, it is only hundreds of years later that we are capable of fully understanding the effect of such a transformational invention. Trying to do the same with social networks few years after they were invented has one impact: it widens the range of understanding which comes with the retrospect of time [4]

Importantly as is true of the World Wide Web and the printing press, naturally, any new innovation having transformative and troublesome capability should be perceived as dialectical. Approximately throughout the first 100 years following Gutenberg's innovation [8] print contributed significantly towards bringing about obvious mistakes as it did in spreading of enlightened truth. It is with this historical observation that any person trying to analyze the responsibility of the social media and the World Wide Web ought to do so with complete dialectical and, more importantly, with complete acknowledgement of present-day subjectivity [4]. As Haas [9] indicate:

The telegraph, printing press, radio and cassettes etc. all created problems to the prevailing order of their day. Similar to these earlier technological innovations, social networks are not decisive. In other words, they could be restrained by governments; simultaneously, they can be used by government to inspire their supporters.

Malcolm Gladwell-a prominent critic of cyber-Utopianism-has indicated that uprisings have been occurring for hundreds of years before Mark Zuckerburg pioneered Facebook. Nevertheless, there is practical proof that, "the first-quarter of 2011 witnessed what might only be considered a significant change in MENA's use of social

*Corresponding author: Badreya Al-Jenaibi, Assistant Professor, Mass Communication Department, UAE University, UAE; E-mail: aljenaibi@uaeu.ac.ae

Received September 22, 2012; Accepted November 15, 2012; Published November 24, 2012

Citation: Al-Jenaibi B (2012)War and the Worlds and the Promise of Social Media Tools. J Mass Commun Journalism 2:130. doi:10.4172/2165-7912.1000130

Copyright: (c) 2012 Al-Jenaibi B. This is an open-access article distributed under the terms of the Creative Commons Attribution License, which permits unrestricted use, distribution, and reproduction in any medium, provided the original author and source are credited. 
networks towards online civil and social mobilization" [10]. Note that the launch of social networks did not cause the Arab Spring. However, they played a vital facilitating task. They did this by "collecting real time information, and facilitating the weak bonds-the physically far-away and socially varied relationship around the world" [10].

\section{Social media networks definitions}

Social media networks are by definition online tools and utilities which permit conveying of information online, and association and participation [10]. It "includes web- and mobile-based technologies"[11]. In addition, social media networks can be defined as websites which relate with the users, whilst providing them information [12]. Clearly, social media networks are typified by a joint nature. This nature is credited to the central role they played in the Arab Spring [10]. The four most extensively used social media networks, Facebook, YouTube, Twitter and blogging will be defined below:

\section{Facebook}

Launched eight years ago as a social networking site solely for Harvard students, this social media website active monthly users as of April 2012 stood at 901 million [13]. Facebook users relate with Facebook friends by writing on other facebook friends walls and by updating their status. An additional method is that they relate with other members by sending direct private messages. Users are able to 'like' pages; at the same time, they can upload photos and videos, and import and search for contacts. They can also create and join interest groups. Interestingly, more than 75 percent of users are situated outside the United States, in spite of its American origin. It worth mentioning that over 350 million Facebook users access their respective accounts through cell phones, an important feature to the role this social media site was used all through the Arab Spring [14]. According to the Arab Social Media Report (ASMR), in the MENA region, as of April 2011, the penetration of this social media network stood at 27,711,504 [14]. Egypt alone has 6,586,260 active users, the largest number of Facebook users of any MENA country [14].

\section{Twitter}

It was launched six years ago, Twitter is a "real-time information social media networking site which connects users to latest information regarding what they find exciting" [15]. Twitter's users converse through "Tweets". These are short posts, restricted to 10 characters, additionally permitting for embedded media links. Users may also "follow" the updates of other members. Examples include traditional media sources like Newsweek or Al-Jazeera, friends and more. Moreover, tweets might be grouped by making use of "hashtags" which play a role of "grouping posts together by subject or category" [10]. For instance, the majority of reputable hashtag in the MENA region for a period of three months beginning January 2011 were ranked number 1Egypt (1.4 million mentions) and Libya were ranked number 2 (990,000 mentions) [10]. Over the same period, in Egypt, there were approximately 131,204 Twitter users [14]. In the capital Cairo, one Twitter user produced 60,000 words; the user produced them all through the 18-day uprising.

\section{YouTube}

It was the first social media website devoted exclusively to uploading and sharing individual video. More than three billon videos are seen on a daily basis on this social media site, reaching seven hundred million in 2010 [16]. In addition to uploading and seeing video, users are also allowed to leave comments on them. It is important to note that YouTube is the third most visited website in the world [17].

\section{Weblogs}

Commonly referred to as a blog, a weblog can be defined as "a simple-to-use content management tool" [18]. When a person 'blogs', that person is directly including new content to their site through a web interface; this process does not require one to have programming skills. Basically, blogging needs Internet access as well as typing skills. It is clear that these low-cost obstacles have contributed to weblogs multiplication globally. There were 40,000 active blogs in MENA region in 2010. This number has increased considerably ever since the uprisings. Towards the end of the year 2011, it was speculated at more than 600,000 weblogs. Notably, this is in accordance with the Arabic Network for Human Rights Information [18].

\section{Theories of communication}

It is no wonder that social media networks have become a valuable vehicle for mobilization. This role may be described by two wellknown theories of communication, one of which Harlod Laswell's "functionalist theory" [19]. The other theory is Mark Granovetter's theory [20]. Although, these theories were developed prior to the advent of social media networks [21], they can be sufficiently used to explain why the Tunisian, Egyptian, Syrian and Libyan activists chose social media for organization of the demonstrations. Laswell's theory offers a logical outline for the study of communication [22]. The theory is founded upon the multi-faced question: Who speaks what in which platform to whom with what outcome? It favors a content approach analysis which is a research method [23]. The method is targeted at attaining an objective and quantitative explanation of the manifest composition of communication [24]. Content analysis is used in the literature review to analyze how the Egyptian, Libyan and Tunisians activists behind the uprisings used social media tools.

In his 1973 study which he called The Strength of Weak Ties, Granovetter [20] analyzed the connection between micro-level communications and macro-level patterns in social networks. $\mathrm{He}$ concluded: "the strength of weak ties lies in their potential for political organization, and social mobility across various networks". Contrasting strong ties, weak ties can spread ideas and information across social groups. Granovetter [20] demonstrates this theory by utilizing the instance of spreading a gossip. As far as the example is concerned, a person can choose to share a gossip with each of his closest friends who are considered strong ties. The closest friends may then choose to spread the rumor to their close friends. In those cases, some persons are liable to hear the gossip many times the reason being that those associated with strong ties have a tendency of sharing information with friends; therefore, it (information) is found in one social group. Once applied to political mobilization, it is without a doubt that the same rule applies Granovetter [20]. To illustrate this, if the activists planning the demonstrations in Tunisia, Egypt and more had only talked to their family members, it not likely that thousands of Egyptians or Libyans or Tunisians would have shown up for the demonstrations Granovetter [20]. Through capitalizing on the weak ties, the activists managed to spread their calls for political mobilization. Forged online by the social networks (Facebook and more), the weak ties also enabled the activists to start a conversation which encouraged the demonstrations Granovetter [20].

\section{Literature Review}

Tunisia was the first country in MENA region to undergo demonstration in December of 2010 [25]. Mohamed Bouazizi set himself on fire in Tunis, Tunisia to protest against police bribery and 
maltreatment. More specifically, the young street vendor took his own life after his vegetable cart was confiscated by the police [26]. His action sparked different violent street protestations. Later, the demonstrations resulted to the falling of President Zine el-Abidine Ben Ali [27]. He was the first president in MENA to fall to mass demonstrations [28]. Ben Ali appeared an unlikely victim since his country enjoyed most excellent educational system and strongest organized labor movement in MENA region [29]. Tunisia also has the largest middle class in the Arab world. Unfortunately, Ben Ali's government tightly limited free expression as well as political parties [30]. News regarding Bouazizi action and the revolution in Tunisia rapidly spread [31] like wildfires with the aid of social media networks [32]. In due course, more than 15 countries in the Arab world started demonstrating against issues such as their corrupt governments [33], inflation, and human rights violations. Through demonstrations, the demonstrators hoped to attain regime change, human rights and much more [34]. Three other countries in the Arab world have ousted their governments: Egypt, Libya, and Yemen [35].

On January 25, 2011, Facebook was used to plan a demonstration rally in Egypt to protest against the state of emergency laws [36] and corruption in high places. On that date, a computer-savvy Egyptian used Facebook to communicate with youths to additionally protest against lack of freedom of speech [37], police brutality and lack of free elections [38], leading to the ousting of President Hosni Mubarak on February 11, 2011 [39]. On February 15, 2011, tens of thousands of Libyans demonstrated following the government's arrests of humanrights attorney [40]. Fathi Terbi was arrested in Benghazi, Libya. His arrest led to military rebellion against Colonel Muammar Gadhafi who was finally captured and murdered on October 20, 2011 near Sirte, Libya [41]. On January 16, 2011, two days following the ousting of Tunisian president, a woman in Yemen posted a message on Facebook [42]. The 32-year old woman message called on the people to rejoice the Tunisian revolution. The Yemeni protests led to the resignation of President Ali Abdullah Saleh on November 22, 2011 [43]. On February 14, 2011, an anti-government rally was planned in Bahrain [44]. In that rally, which was encouraged by chaos in Egypt and Tunisia, a demonstrator was murdered. On March 13, 2011, Syrian security personnel opened fire on persons who had assembled in a mosque in a city called Deraa to deliberate regarding the manner in which to react to arrest of some students. These students had written ant-regime slogans on their school walls [43]. The uprising in Syria resulted to a civil war which is currently going on with President Bashar Assad still clinging to power; it has resulted to deaths of thousands of people.

At this point, it is clear that the Arab Spring is a result of people of MENA being tired of ruled under dictatorship [45]. For many years before the uprisings, the people of MENA were ruled by dictators [31], some of whom have been in power for decades. That made it more difficult to remove them from power [46], since these dictators did not allow the people of MENA to exercise their democratic rights through voting [47]. They were fed up and opted to oust the dictators through demonstrations to pave way for a democratic government [48]. To counter these revolutions, the dictators employed forceful tactics to keep them in power [49] which is no wonder that many demonstrators were arrested; some were severely injured; others were murdered.

\section{The role of social media tools in the Arab Spring}

In a bid to completely assess the role played by the social media networks in these uprisings, several resources will be analyzed. They include journalistic articles and academic articles. The role of the media tools will be analyzed by paying attention to several trends, one of which is social media as a substitute press for the citizen journalism [50]. The other trends include social media as a planning tool, and as a weapon for producing awareness in the MENA region and other regions of the world.

\section{Social media as a substitute press}

Characterized by low entry barriers, social media networks offer an accessible platform [51] for citizen journalism. Citizen journalism can be referred to as using digital medial tools with the aim of reporting on events. Then, text and videos are uploaded directly to the World Wide Web. As an alternative, the information and videos [52] can be fed to media outlets [53]. In MENA, during the uprisings, the conversation taking place through social media networks was utilized by mainstream media [40] in one main way: as a source throughout the period in which the demonstrations lasted. Specifically, Al-Jazeera depended on Twitter users and well-established bloggers [26]. They depended on them for real-time reporting of events by using Sharek; it is a citizen's media platform which obtained and then filtered information [54] supplied by citizen journalists. The tactic faired very well by trying to recognize major bloggers in nations before the demonstrations erupted to serve as citizen reporters. Then, the bloggers were to substantiate information later on [55].

Although apparent accuracy issues associated with citizen journalism exist, the outcome for the responsibility played by social media tools in Arab Spring is that they permitted people directly involved to expose themselves to a global audience. Enabling the demonstrators to shape their own story and creating connected activists capable of contesting information-controlling abilities of dictatorial regimes, social media tools placed the tools of truth-telling in the hands of ordinary citizens. Interestingly, there is an increasing criticism of a western narrative which is shaping how the globe perceives the Arab Spring, and which is very well defined by George Friedman who defines it as the postulation pioneered by the mainstream media that the uprisings in MENA were political and that they were perpetuated by the citizens in order to demand broadminded democratic change. Central to Friedman's argument is that the revolutions were supported by Western democracies and their (the revolutions) key objective was to generate political change across MENA and that social media were extensively used as a facilitating tool [56]

Because Facebook, Twitter and other social media networks originated in Western countries, it has been argued that their use in assisting demonstrators to successfully oust their dictators has given rise to the "hegemonic debate" [57] of a technologically-advanced West assisting the less-developed non-West.

Using Twitter to illustrate how social media tools were used as an alternative press during the Arab Spring and using the Egyptian revolution as an example, Twitter was mainly used as a means of offering firsthand accounts of occurrences on the ground. Due to the fact that Twitter is a cell-phone-enabled social media having embedding abilities, users were able to tweet updates each minute; they managed to incorporate other forms of media like videos and photos. Just as an example, on January 26, 2011, one Twitter user tweeted: “At this moment in front to my eyes, they arrested some demonstrators and beat others" [58]. On January 29, 2011, a different demonstrator named Gigi tweeted: "The state-owned media is not showing anything from what is actually taking place by attempting to diminish it" [59].

Classic examples like these suitably illustrate how Twitter users served like an alternative press. In doing this, they self-published their 
own experiences with the revolutions occurring; as a result, they offered their side of their story of the occurrences which were revealed to both local and global audience. In this manner, social media tools permits people who are geographically far away to follow occurrences literally in real-time. As the revolutions persisted, in Egypt, for example, the government shut down the internet. Even as it did this, several persons outside Egypt decided to continue the momentum. Using technology to bridge the geographical barriers, these persons were able to continue providing coverage of occurrences. As an example, an American graduate student was able to communicate with Egyptian friends through cell phone. John Scott-Railton did this in a bid to collect their observations of the continuing demonstrations; then, he translated them into tweets for his followers numbering 4000. It with this example in mind that social media played a crucial role in bringing people who are located far away from where the events are taking place to context and analysis during the Arab Spring [60].

\section{Social media as a planning tool}

Starting with virtual networks, the Arab Spring was greatly fuelled by effective use of social media; later on, it was transposed to offline networks. At the time of the revolutions, in MENA region, activists managed to play off the strengths of social media networks abilities of Twitter and Facebook by taking advantage of social media central characteristic of transmitting information quickly, an aspect of any digital media. In addition to high speed of transferring information, social media networks are also typified by "many-to-many" [61] communication abilities. For example, a Facebook Group called "We are All Khaled Said" acted like a planning platform in Egypt. Created by activist Wael Ghonim, this group attracted like-minded persons to link over a common interest with the aim of commemorating Khaled Said. Most specifically, the group was formed to honor the cruel assassination of the Egyptian blogger who perished at the hands of security forces. The group attracted more than half a million members. This transformed to a common interest in creating resistance to the security forces, which further transformed into a movement to compel President Mubarak to resign [62]. Allowing different activist networks to converse with each other, Facebook played a crucial role of providing an important platform for potential demonstrators to share their grievances [61]. Once individuals discovered that other persons would be taking part in demonstrations, they were more liable to also take part in the demonstrations. In due course, a tipping point resulted as the demonstration turned out to be self-strengthening, and escalated without additional organization by the leadership [57]. Immediately after the plans for protests were finalized, the word was spread all through offline communities. The reason is that it was important to reach most of the population that remained offline.

\section{Social media networks as creating awareness}

Facebook was extensively used in the Arab Spring to generate awareness. A classic example is Wael Ghonim's group. Members spread the graphic photos of Said's disfigured dead body all over the World Wide Web. In this manner, Facebook's networking abilities were used to engage in an efficient cyber activism campaign against the oppressive Egyptian state. It is without a doubt that social media networks permitted the people of MENA to challenge the monopolies of power in their respective countries [10]. A definite change in mind-set towards the governments surfaced; that was clearly a collective change which was fuelled by use of social media. Hofheinz [63] terms the use of social media during the uprisings in MENA as copy and paste trend. What news the people of MENA read, what they chat about, and what they think is dictatorial is increasingly determined by either the links forwarded to them by their colleagues on Facebook or what is shared to them by their friends on Twitter. Social media networks played a crucial role in creating this shift in social awareness. In accordance with Slim Amamous, collective awareness emerged through the Internet due to the fact that it is immediate. Amamous, who is a Tunisian blogger, hence concludes, "Cyber activists as a result managed to take advantage of rapid speed of communication of social media networks to create a social movement which can be shifted to the offline society and subsequently become evident in political actions" [1].

A final component to address is the means in which social media accelerated awareness of the continuing revolutions in the Arab world in the international community. A case surfaced for the requirement for social networking tools to persist political mobilization in Egypt. In that case, two Western companies (Google and Twitter) partnered to provide "Speak2Tweet" services. The move was triggered by President Mubarak's command to switch off the internet across Egypt. A Lebanese named Habib Haddad teamed up with the two western companies to translate Arabic tweets. Haddad, who is a technology entrepreneur, partnered with the companies to organize 1,000 translators to interpret the tweets into English, German, and French [1].

\section{Research Methodology}

The study used a multi-method approach, that is, qualitative (interview themes) and quantitative (survey analysis). There are a few reasons for this. This approach helps to get complete answers and raises the robustness of people's understanding [64]. Multi-method verifies interpretations of what is taking place in a given environment $[65,66]$. Enriching researchers understanding of particular situations owing to its analytic power, mixed-research enables researchers to broaden their scope of study and factor in other characteristics of the phenomenon [66-68]. Finally, multi-method research places the researcher in a position to discover new factors which might encourage future research $[66,69]$.

The qualitative part centered on persons in official positions of power. It comprised of the analysis of data from interview with 27 employees from the following organizations: Abu Dhabi media company (nine of them), Sha'aer Al Malion Channel (one), one works as a visual artist in a free agency, one works art an art production firm, those that are independent were five, one working in $\mathrm{Al}$ Ain municipality, three at Al Fajr newspaper, three at Dubai Medi-Nour Dubai, and two at Abu Dhabi Media-Al Etttihad newspaper. These interviewees comprised both male and females aged between 20 and 50. All participants hold high school, B.A., and Master degrees. For the quantitative part, surveys were distributed to 600 people. About 454 surveys were received back which is a good number.

\section{Interview questions and results}

Research questions: The study examines the following research questions:

1) What is the role of the social media in changing the UAE and Arab media democracy?

2) Can the social media increase the press and media freedom and why?

3) Can the social media replace the use of the old media, (newspapers, TV channels. etc.) why? 
4) Do you prefer to use the social media and post your news online? Why?

\section{Role of social media during the revolutions in MENA region}

With reference to the political uprisings in the Arab world, most interviewees emphatically stated that social media is becoming one increasingly crucial factor in guiding the manner in which people in the Arab world live and relate in their internationally connected world. In addition, social media tools have placed a crucial role, particularly when in comes to planning, mobilizing, providing up-todate information, and serving as a morale boost of great immediacy to activists or demonstrators taking part in political or social change. One interviewee indicated that millions of online contributors are forming and sharing content across the Arab world; at the same time, they are influencing the news and information channels across MENA. There was agreement that democracy has ultimately come to parts of the Arab world; the "Arab Spring" in Tunisia, Egypt and other countries across the region extensively depended on the Internet, social media networks such as Facebook, Twitter, TwitPuc, and YouTube within the initial stages to fuel the social demonstrations. Arab governments will be expected to get used to the changing Arab media landscape as increasing numbers of Arabs become internet-savvy; to attain this, they will require support from the international community. One interviewee concluded that there are two most encouraging development's in Arab world's modern-day history: The first is growing checks on government power. The second factor is the role of media in the democratic process. Another interviewee had different views: People demonstrated to make the governments open the door for dialogue and that the social media networks enabled the demonstrators to exchange opinions; some of the issues that made the protestors to take part in the demonstrations are: poverty, hunger, injustice and oppression. Through two social media networks, namely, Facebook and Twitter, protesters managed to collect up-to-the-minute information regarding events, participants and leaders. Just as an example, 90,000 people in one case responded through both Facebook and Twitter that they organized certain protests.

\section{Role of social media in public discourse in the United Arab Emirates}

Besides creating political awareness, social media has played other roles in the United Arab Emirates. One interviewee said that social media has played a big role in motivating people. It creates successfully new channels that enhance people's interactions with the national and international events by enabling them to provide their comments and points of views. For this reason, the traditional media is no longer the sole news transcriber. As a matter of fact, the social media in the United Arab Emirates focuses on religious and cultural issues not political issues. Nevertheless, in the Arab world where people suffer, the social media becomes their only breather to express their grievances, and their demands can make key changes in the country, such as resignation of government officials and even the president as was the case in Tunisia, Egypt and more. Social media is providing a platform for freedom of expression, and any person who gets access to the social media can expose his ideas and thoughts freely; these states of affairs were not possible with the traditional media. As for the economic matters, nowadays, in the United Arab Emirates, many people routinely look up for business and purchasing information on the World Wide Web and seek recommendations and views through social media. Social media enables individuals to relate the different slides of the community together. On the contrary, the interviewee pointed out that social media provides an unofficial window to share news, opinions, and discussions in a bad way. Overall, however, in the United Arab Emirates, social media is meant to bring about development and not destruction as was the case in Tunisia, Egypt and more.

\section{Social media is not likely to replace old media (newspapers,} TV channels and so on)

Some interviewees agreed that social media can replace the use of old media while others indicated that it can perhaps do so. One who did not agree said that social media is not meant to replace old media, but rather it is a savior and promoter to the noble cause of preserving the time tested old media techniques. One of those interviewees who agreed indicated that it could replace old media because it cost nothing and that social media tools deliver information quickly. Those who said perhaps emphasized that in spite of social media having the potential to replace the old media, the old media still remains reputable amongst some people and thus we cannot eliminate it completely. One interviewee in this category of interviewees said that traditional media is still the best and efficient way of communication and it will maintain this for a long time, but the only thing that it should follow is the prosperity of social media. It is due to the legitimacy and consistency of the social media. On a negative note, this interviewee was quick to point out that social media cannot replace old media owing to its limitation. The interviewee predicted that old media would remain at least in the next one or two decades. However, old media in the United Arab Emirates faces two challenges, the first being how to become more transparent and free. Secondly, there are some people how find it difficult to adopt new media into their businesses. Because it is easier to communicate with people using social media, more and more people are switching from the old media to the new media. Despite the fact that social media is an important tool for marketing, there are some people, especially the old ones who prefer various forms of old media such as the television and daily newspaper.

\section{Disagreement about media censorship}

Some respondent agreed that social media has not vanished media censorship while others believed that it has. One of those who disagreed claimed that censorship is everywhere and thus we cannot hide from it. A different interviewee who disagreed indicated that social media cannot make censorship to disappear completely, and that a small mistake in the social media might result to a big problem. A third interviewee who disagreed believed most people trust the media as the main source of censorship and we can screen news on social media, and hence social media cannot eradicate media censorship. The interviewee further claimed that there is a clear media censorship from some administrative authorities in many of the Arab countries, including the UAE. One of those who agreed that social media wiped out media censorship asserted that social media invented the freedom and that if there were media censorship, we would not have witnessed the revolutions across the Arab world. Furthermore, social media allowed the public to break some social and political taboos, and people became more critical about issues they think they have the right to express. Social media gave them this privilege, while traditional media was an obstacle owing to censorship.

\section{Common agreement about posting news online via social media}

There was a common agreement that social media adds a new dimension to the old media, which is characterized greatly by one-way traffic. Social media adds the new dimension by allowing 
customers to engage in meaningful conversations with a company or an organization. People just love to talk back, and old media offered limited opportunities to do so. With social media, customers have a great opportunity to speak their minds and provide feedback. Social media thus further leads to numerous untapped opportunities. However, it was noted that for maximum impact to occur, users need to understand when to target the audience. In other words, if someone posts news at the wrong time of the day, there is a high chance that it might get buried by other posts by the time traffic reaches its peak.

\section{Survey Questions and Results}

1. How often do you make use of the following search tools when following, sharing or posting news and information? Ten search tools were included in this question: Google, Yahoo!, Ask, Icerocket, Bing, Twitter Search, StumbleUpon, Technorati, Wikipedia, and News Aggregator (FeedDemon, Firefox, \& RSSOwl).

The median value for those who stated that they never use these search tools is 204; it gives us an idea that many respondents never use Ask, Bing, StumbleUpon, and Technorati search tools. The median value for those who indicated "rarely" is 65.5 which show that many respondents rarely use Yahoo! Search, Ask, Bing, Twitter Search, and News Aggregator. For those who indicated "sometimes," the median is 82 , pointing out that quite a number of people sometimes use Yahoo! search, Ask, Wikipedia and News Aggregator. For those respondents who indicated "frequently," the median is 34.5 , which signify that only a few respondents frequently use Yahoo! Search, Icerocket, Bing, StumbleUpon and Technorati search tools. Finally, the median of those respondents who stated "Every time" is 23, which indicates that many of the respondents use Google, Wikipedia and Twitter Search for sharing or posting news and information.

\section{Hypotheses testing}

H1a: There is a negative correlation between the frequency of usage of Google and Yahoo! search tools amongst respondents.

A strong negative correlation was found between respondents' responses regarding their use of Google and Yahoo! search tools $(r=$ $-0.665, \mathrm{p}=0.111$ ). In other words, most of the respondents tend to use either Google or Yahoo! frequently but not both because they appear to have similar features. However, there are more respondents who prefer Google search tool than Yahoo! The hypothesis was accepted.

H1b: Frequency of usage of Bing correlates positively with that of usage of Twitter search tool amongst the respondents.

A strong positive correlation was found between Bing and Twitter Search $(r=0.954, p=0.006)$. Putting it differently, even though the respondents to use both of these search tools frequently, more of them tend to use Ask than Icerocket. The hypothesis was accepted.

H1c: There is a negative correlation between the frequency of usage of Ask and Icerocket amongst the respondents.

A strong positive correlation was found between Ask and Icerocket Search $(r=0.958, p=0.005)$. In other words, though the respondents prefer to use both search tools frequently, there are more who use Twitter Search than Bing. The hypothesis was rejected.

H1d: There is a positive correlation between the frequency of usage of StumbleUpon and Technorati search tools amongst the respondents.

A very strong positive correlation was found between the frequency of usage of StumbleUpon and Technorati search tools $(\mathrm{r}=1.0, \mathrm{p}=1.839)$.
In other words, the respondents use both search tools frequently since they have different features. The hypothesis was accepted.

H1e: There is a positive correlation between the frequency of usage of Wikipedia and News Aggregator (FeedDemon, Firefox, RSSOwl, etc.) search tools amongst the respondents.

A weak negative correlation was found between the frequency of usage of Wikipedia and News Aggregator (FeedDemon, Firefox, RSSOwl, etc.) $(r=-0.395, p=0.255)$. In other words, the respondents tend to use frequently either Wikipedia or News Aggregator. Nevertheless, more of them tend to use Wikipedia than News Aggregator. The hypothesis was rejected.

\section{How often do you}

a) Visit an old media site subsequent to finding out a news story via social media tools?

b) Visit a corporate web site subsequent to finding out a news story via social media tools?

c) Make use of a social media tool to verify information collected via old media outlet?

d) Make use of an old media to verify information collected via a social media tool?

e) Make use of social media tools to verify information collected via a corporate website?

f) Make use of social media tools to verify information collected via a press release?

The median of the respondents who stated "never" is 71.5. It points out that some of the respondents never utilize social media tools to verify information collected via a corporate website. Likewise, they never use social media tools to verify information collected via a press release; some never visit a corporate website subsequent to learning of a news story via social media tools; for those respondents who indicated "rarely," the median is 118.5 ; it indicates that several respondents rarely visit an old media site subsequent to discovering a news story through social media tools; also, they rarely utilize social media tools to verify information collected via a press release; the median for those respondents who stated "sometimes" is 168.5; it indicates that many respondents sometimes visit an old media and corporate site subsequent to finding out a news story through social media tools; for the respondents who stated "frequently," the median is 64; it shows that few respondents visit an old media and corporate site frequently subsequent to finding out a news story through social media tools. Still, few respondents use social media tools to verify information collected via a press release. Lastly, for those respondents who stated "many times," the median is 29 , pointing out that few respondents visit traditional and corporate sites subsequent to learning of a news story via social media tools. Furthermore, few respondents use traditional and social media tools to verify information collected via a press release.

H2a: Visiting an old media site subsequent to discovering a news story via social media tools correlate negatively with visiting a corporate website subsequent to discovering a news story via social media tools.

Since there is a very strong positive correlation between visiting a traditional media site and corporate website after learning of a news story through social media tools $(\mathrm{r}=0.981, \mathrm{p}=0.002)$, this hypothesis was rejected. In other words, the respondents favored visiting both sites 
after learning of a news story via social media tools, though more visit traditional media sites frequently than corporate sites.

H2b: Utilizing a social media tool to verify information collected via an old media outlet correlate positively with utilizing an old media to verify information collected via a social media tool.

A very strong positive correlation was found between using a social media to verify information collected through an old media outlet and utilizing an old media to verify information collected via a social media tool $(\mathrm{r}=0.989, \mathrm{p}=0.001)$. In other words, the respondents use both media tools to fact-check information of either media tool, although more of the respondents tend to use a social media tool to fact-check information via a traditional outlet. The hypothesis was accepted.

H2c: Using social media tools to verify information collected via a corporate website correlate negatively with using social media tools to verify information collected via a press release.

A very strong positive correlation was found between using social media tools to verify information collected via a corporate website and utilizing social media tools to verify information collected via a press release $(\mathrm{r}=0.982, \mathrm{p}=0.001)$. The very strong positive correlation means that the respondents tend to use social media tools frequently to verify information collected via corporate and press release site. However, a smaller number of more of them tend to use social media tools in a bid to verify information collected via a corporate release. The hypothesis was rejected.

\section{Social media attitudes}

a) Do you believe news collected via social media sources is more or less reliable as compared to news collected through old media news sources?

b) Do you believe news collected through social media sources is more or less accurate as compared to news collected through old media news sources?

c) Do you believe news collected through social media tools is more or less timely as compared to news collected through old media news sources?

The median value of those respondents who stated "much more timely" is 57 . This shows that many respondents agreed that news gathered via social media is timelier than that via traditional news sources; for those who stated "slightly more reliable," the median is 119 , pointing out that many respondents believed that news gathered via social media is slightly more reliable than that via traditional news sources; for those respondents who stated "about the same," the median is 155 . As per this median, it can be concluded that more respondents believed that news gathered via social media sources and that via traditional sources is about the same in terms of punctuality than in terms of reliability. The median value for those respondents who indicated "slightly less reliable" is 82 . As per this median, many respondents strongly believed that news gathered via social media is slightly more reliable in terms of accuracy and reliability. Finally, the median of the respondents who indicated "much less reliable" is 36 . From this median, a good number of the respondents agreed that news gathered via social media is much less reliable than that via traditional news sources.

H3a: News collected through social media sources is more or less reliable as compared to news collected through old media news sources correlate negatively with news collected through social media sources is more or less accurate as compared to news colleted through old media news sources.

A very strong positive correlation was found between news collected through social media sources is more or less reliable as compared to news collected through old media sources and news collected through social media sources is more or less accurate as compared to news collected via old media sources $(\mathrm{r}=0.972, \mathrm{p}=0.003)$. In other words, the respondents believed that news collected through social media sources is much more reliable and accurate as compared to that collected through old media sources. However, more of the respondents believe that news gathered via social media tool is more reliable over traditional news sources as compared those who believed it is accurate over that via traditional news sources. The hypothesis was rejected.

H3b: News collected through social media sources is more or less reliable as compared to news collected through old media news sources correlate positively with news collected via social media sources is more or less timely as compared to news collected through old media sources.

A very strong positive correlation was found between news collected through social media sources is more or less reliable as compared to news collected through old media news sources and news gathered via social media sources is more or less timely as compared to news collected through old media news sources ( $r=0.931, \mathrm{p}=0.011)$. In other words, respondents believed that news gathered via social media sources is much more reliable and timely than that gathered via traditional news sources. Nonetheless, more of the respondents believe that news gathered via social media tools is about the same in terms of timeliness as that through traditional news than those who indicated about the same in terms of reliability. The hypothesis was accepted.

\section{How important have}

a) Social media tools (Facebook, Twitter, YouTube, and so on) turn out to be for following or screening news and information?

b) Social media tools (Facebook, Twitter, YouTube, and so on) turn out to be for sharing or suggesting news and information?

c) Social media tools (Facebook, Twitter, YouTube, and so on) turn out to be for posting or writing news and information?

The median value for "important" is 182 ; it signifies that many respondents greatly agreed that social media tools have turned out to be significant for following or screening news and information. Also, a good number of the respondents agreed that the tools have become an important tool for sharing/recommending news and information; for those who stated "somewhat important," the median is 141 , indicating that many of the respondents agreed that social media tools are somewhat important for posting/writing news and information; for those who stated "neither important nor unimportant," the median is 81; this points out that quite a number of the respondents believed that social media tools are neither significant nor unimportant for sharing/ suggesting news and information; for those who stated "somewhat unimportant," the median is 28 . Quite a number of the respondents believed that social media tools have become fairly insignificant; they have turn out to be fairly insignificant for posting or writing news and information. Ultimately, for the respondents who stated "unimportant," the median is 16 . From this median, these respondents seem to believe that social media tools have become unimportant for posting/writing news and information. Overall, however, there were a small number of the respondents who agreed that social media 
tools have become unimportant for following/monitoring/sharing/ recommending/posting/writing news and information.

H4a: There is a positive correlation between social media tools have turn out to be significant for following or screening news and information and social media tools have turn out to be significant for sharing or suggesting news as well as information

A very strong positive correlation was found ( $r=0.993, r=0.0003$ ). In other words, the respondents believed that social media tools have become important for following, monitoring, sharing, and recommending news and information. The hypothesis was accepted.

H4b: Social media tools have turn out to be important for following or screening news and information correlate positively with social media tools have turn out to be significant for posting/writing news and information.

Since there is a very strong positive correlation between social media tools have become important for following and monitoring news, and information and social media tools have become important for posting and writing news and information, this hypothesis was accepted $(\mathrm{r}=0.987, \mathrm{p}=0.0009)$. In other words, only a very small number of the respondents believe that social media tools have not become important for following, monitoring, posting, and writing news and information.

\section{Event Recall and Spreading Speed}

a) Thinking back, how and/or where did you first learn regarding Egyptian revolution?

b) Subsequent to discovering Egyptian uprising, did you utilize any of the following to share or spread this news?

c) Thinking back, how and/or where did you first learn concerning Libyan, Tunisian and Syrian revolutions?

d) And subsequent to learning about Libyan, Tunisian and Syrian uprisings, did you utilize any of the following to spread or share this news?

Social and traditional media tools or methods of spreading/ learning/hearing news that were asked are newspaper, television, radio, Facebook, Twitter, Blog, word-of-mouth, email, mobile device (cell/ smart phone, PDA etc.), and other.

The median of the respondents who indicated "Newspaper" is 57, signifying that many of these respondents learned the Egyptian revolution via the newspaper. For the respondents who stated television, the median is 181, pointing out many of this category of respondents learned the Egyptian, Tunisian, Libyan and Syrian revolutions via the television. For those who stated "Radio," the median is 28.5. This shows that most of these respondents use the radio after learning the Libyan, Tunisian, and Syrian revolutions to spread or share the news. As far as blog is concerned, the median is 8.5 , indicating that many of the respondents who stated "Blog" used it learned first about the Libya, Tunis, and Syria revolutions via it. For those respondents who stated "Facebook," "Twitter," "Word-of-Mouth," "E-mail," "Mobile Device," and "Other," the medians are 57, 49, 19, 9, 27.5, and 26.5 respectively. From these medians, it is not difficult to conclude that these respondents used these devices/techniques after learning of Egyptian, Libya, Tunis, and Syria revolutions to spread/share the news.

H5a: Where the respondents first learnt about Egyptian revolution correlates positively with after learning the Egyptian revolution they used the following to spread or share this news: newspaper, television, radio, Facebook, Twitter, blog, word-of-mouth, e-mail, mobile device and other.

A very strong positive correlation was found between learning first about the Egyptian revolution and using newspaper, television, radio, Facebook, Twitter, blog, word-of-mouth, e-mail, mobile device and other to spread this news $(\mathrm{r}=0.955, \mathrm{p}=8.287)$. In other words, the more the respondents learnt about the Egyptian revolution, the more they used newspaper, television, radio, Facebook, Twitter, blog, word-ofmouth, e-mail, mobile device and other to spread or share the news. The hypothesis was accepted.

H5b: Where the respondents first learnt about Libyan, Tunisian and Syrian revolution correlates positively with after learning the Libya, Tunisia, and Syria they used the following to spread or share this news: newspaper, television, radio, Facebook, Twitter, blog, word-ofmouth, e-mail, mobile device and other.

A very strong positive correlation was found between where the respondents first learnt about Libya, Tunisia and Syria revolution and after learning the Libya, Tunisia, and Syria they used the following to spread or share this news: newspaper, television, radio, Facebook, Twitter, blog, word-of-mouth, e-mail, mobile device and other $(\mathrm{r}=0.875, \mathrm{p}=0.0004)$. In other words, the more the respondents learnt about the Libyan, Tunisian, and Syrian revolutions, the more they tended to make use of the following to share or spread the news: newspaper, television, radio, Facebook, Twitter, blog, word-of-mouth, e-mail, mobile device and other. The hypothesis was supported.

Which of the following social media tools do you use mainly to follow, post, and share news and information (Must choose at least 5 sources):

MySpace, Craiglist.org, Facebook, Blogger, Propeller, Now Public, Link swarm, Met filter, Topix.com and Digg, Wikipedia, Helium. com, EarthFrisk, AssociatedContent.com, Reddit, Slashdot, YouTube, Wunderground, LinkedIn, Stirrdup and Shutterstock.com, Yahoo! News, Truemors, FindArticles.com, The Onion.com, Linkfilter, Plime, SumbleUpon, Twitter, NewsCloud, Google News and Other?

The median was calculated (11.5), from which it can be concluded that most respondents use YouTube, Twitter, Facebook, Google News and Wikipedia to follow, share, and post news and information. Some of the social media tools that are not commonly used include StumbleUpon, Associated Content.com, Slashdot, Topix.com and Digg, Link swarm, Craiglist.org, Wunderground, Stirrdup and Shutterstock.com, Plime, Truemors, Linkfilter, and The Onion.com. Those social media tools that are moderately used include Yahoo! News, Other, Blogger, and MySpace.

H6a: Using Facebook, MySpace, Linkeldln, Yahoo! News, and Craiglist.org to follow, post, and share news and information correlate negatively with using Blogger, Propeller, Now Public, Link swarm, and Met filter.

A very weak negative correlation was found between using MySpace, Linkeldln, Yahoo! News, Craiglist.org, and Facebook to follow, share, and post news and information and using Blogger, Propeller, Now Public, Link swarm, and Met filter to follow, share, and post news and information $(\mathrm{r}=-0.127, \mathrm{p}=0.419)$. In other words, most of the respondents tend to use MySpace, Linkeldln, Yahoo! News, Craiglist.org, and Facebook to follow, share, and post news and information than Blogger, Propeller, Now Public, Link swarm, and Met filter. The hypothesis was accepted. 
H6b: Using Topix.com and Bing, Wikipedia, Helium.com, Earthrise, and AssociatedContent.com to follow, share, and post news and information correlate negatively with using Reddit, Slashdot, YouTube, Wunderground, and Stirrdup and Shutterstock.com.

Because a weak negative correlation was found between using Topix.com and Bing, Wikipedia, Helium.com, EarthFrisk, and AssociatedContent.com and using Reddit, Slashdot, YouTube, Wunderground, and Stirrdup and Shutterstock.com ( $\mathrm{r}=-0.248$, $\mathrm{p}=0.344$ ), the hypothesis was supported. Putting it differently, the majority of the respondents use Reddit, Slashdot, YouTube, Wunderground, and Stirrdup and Shutterstock.com. Only a few of them use Topix.com and Bing, Wikipedia, Helium.com, EarthFrisk, and AssociatedContent.com.

H6c: Using Truemors, Find Articles, the Onion.com, Linkfilter, and Plime to follow, share, and post news and information correlate negatively with using StumbleUpon, Twitter, News Content, Google News, and other.

A strong positive correlation was found between using Truemors, Find Articles, The Onion.com, Linkfilter, and Plime to follow, share, and post news and information and using SumbleUpon, Twitter, News Content, Google News, and Other $(r=0.703, p=0.093)$. In other words, the majority of the respondents use Truemors, Find Articles, The Onion. com, Linkfilter, Plime, StumbleUpon, Twitter, News Content, Google News, and other to follow, share, and post news and information, though a small number of them tend to use Truemors, Find Articles, The Onion.com, Linkfilter, and Plime than StumbleUpon, Twitter, News Content, Google News, and others or the other way round. The hypothesis was rejected.

\section{Social media tools interests}

a) When sharing, posting or following news and information via Facebook, I am most interested in:

b) When sharing, posting or following news and information via Twitter, I am most interested in:

c) When sharing, posting or following news and information via blogs, I am interested in:

The medians for the respondents who stated they are interested in "Local news," "International news," "Entertainment news" are 116, 90, and 48 respectively. They show that more respondents use Facebook to follow, share or post information regarding these categories of news than in using blogs. For the respondents who stated "National news," the median is 65 , signifying that more respondents use Twitter in following, sharing or posting national news than those who stated they use Facebook. As for the respondents who indicated "Sports," and "Business and Financial news," the medians are 36 and 18 respectively, showing that more respondents use Facebook and blogs than Twitter in following, posting or sharing these categories of news. Meanwhile, for the respondents who stated "Weather," the median is 21 . This signifies that more respondents use blogs in following, sharing or posting weather news than Facebook. Lastly, for those who stated they do not use Twitter, the median is 53 , indicating that fewer respondents do not use Twitter to follow/share/post news on blogs as compared to those who use Facebook.

H7a: Respondents' usage of Facebook in following, sharing, or posting various categories of news (local, national, international, sports, and more) correlate positively with respondents' usage of Twitter in following, sharing, or posting various categories of news.
A very strong positive correlation was found between respondents' usage of Facebook in following, sharing, or posting various categories of news correlate positively with respondents' usage of Twitter in following, sharing, or posting various categories of news $(r=0.943$, $\mathrm{p}=0.0002$ ). In other words, there was a common agreement and/or frequent usage of both Facebook and Twitter in following, sharing, or posting the various categories of news. The hypothesis was accepted.

H7b: Respondents' usage of Facebook in following, sharing, or posting various categories of news correlate positively with respondents' usage of blogs in following, sharing, or posting various categories of news.

Since a very strong positive correlation was found between respondents' usage of Facebook in following, sharing, or posting various categories of news correlate with respondents' usage of blogs in following, sharing, or posting various categories of news ( $\mathrm{r}=0.803$, $\mathrm{p}=0.008$ ), this hypothesis was supported. Putting it differently, there was a common agreement regarding frequent usage of both Facebook and blogs in following, sharing, or posting the various categories of news, though a small number of the respondents tend to use Facebook more than blogs.

\section{Discussions}

The study examined role of social media during the Revolutions in four countries of the MENA region: Egypt, Tunisia, Libya and Syria. Also, the study examined the role of social media tools in the United Arab Emirates. The majority of the interviewees agreed that social media is turning out to be one increasingly significant factor in guiding how the inhabitants of MENA countries live and relate in their globally connected world. In the United Arab Emirates, social media has played a big role in motivating people. It creates successfully new channels that enhance people's interactions with the national and international events by enabling them to provide their comments and points of views. For this reason, the traditional media is no longer the sole news transcriber. In fact, the social media in the United Arab Emirates focuses on religious and cultural issues, not political issues. Similarly, they found that in both Tunisia and Egypt, Facebook was used solely to raise awareness, and to spread information during the revolutions [14]. Facebook also played a crucial role in enabling the activists to organize the demonstrations. Most of the interviewees agreed that social media is not likely to replace old media (Newspapers, TV channels and so on). Likewise, Sakr [68] found that national and transnational Arab TV channels have increased considerably to over 200. While some interviewees agreed that social media has not vanished media censorship, others believed that it has. For those who indicated that media censorship has not vanished, stated the opposite; in states such as Syria and Saudi Arabia, the media is still a highly centered appendix to the ruling regimes. However, in the majority of the countries in MENA region, a public domain has surfaced. The public domain has changed the fundamental character of public discourse. More specifically, it has changed it from the propaganda model to a relatively open domain. However, there was a common agreement that social media adds a new dimension to the old media, which is characterized greatly by oneway traffic. Andrew \& Galak [70] found that social media has larger performance impact than old media; thus managers should assess investments in social media.

Discussing the quantitative results, in the United Arab Emirates, many of the respondents never use Ask, Bing, StumbleUpon and Technorati search tools. Also, many respondents rarely use Yahoo! Search, Ask, Bing, Twitter Search, and News Aggregator. Nonetheless, 
quite a number of people sometimes use Yahoo! Search, Ask, Wikipedia and News Aggregator. Only a few respondents frequently use Yahoo! Search, Icerocket, Bing, StumbleUpon and Technorati search tools. Finally, many of the respondents use Google, Wikipedia and Twitter Search for sharing or posting news and information. The study found a strong negative correlation between respondents' responses regarding their use of Google and Yahoo! search tools. In other words, most of the respondents tend to use either Google or Yahoo! frequently but not both because they appear to have similar features. The study found a strong positive correlation between Bing and Twitter Search, a strong positive correlation between Ask and Icerocket, a very strong positive correlation was found between the frequency of usage of StumbleUpon and Technorati search tools, and a weak negative correlation was found between the frequency of usage of Wikipedia and News Aggregator.

The study found that some of the respondents never use social media tools to verify information collected via a corporate website; some never use social media tools to verify the information collected through a press release. Some respondents never visit a corporate website subsequent to learning of a news story via social media tools; several of them rarely visit a traditional media subsequent to discovering a news story via social media tools; a number of them rarely utilize social media tools to verify information collected via a press release; several respondents sometimes visit an old media site and corporate site subsequent to discovering a news story via social media tools. Few respondents visit traditional media and corporate sites frequently. They visit them frequently subsequent to finding out a news story via social media tools; also, few respondents utilize social media tools to verify information collected via a press release; lastly, few respondents visit traditional and corporate sites subsequent to finding out a news story via social media tools. As well, few respondents use old and social media tools to verify information gathered through a press release. A very strong positive correlation was found between visiting an old media site and corporate website subsequent to finding out a news story via social media tools. Similarly, a very strong positive correlation was found between using a social media to verify information collected via an old media outlet and utilizing an old media to verify information collected via a social media tool. Also, a very strong positive correlation was found between using social media tools to verify information collected via a corporate website and utilizing social media tools to verify information collected via a press release.

The study found that respondents agreed that news collected through via social media is timelier as compared to that via traditional news sources. Many of the respondents believed that news collected through social media is slightly more reliable as compared to that via traditional news sources. More respondents believed that news collected through social media sources and old media sources is about the same in terms of punctuality as compared to in terms of reliability. Finally, several respondents agreed that news collected through via social media is much less reliable as compared to that via old media news sources. A very strong positive correlation was found between news collected via social media sources is more or less reliable as compared to news collected old media news sources and news collected via social media sources is more or less accurate as compared to news collected via old media news sources. Likewise, a very strong positive correlation was found between news collected through social media sources is more or less reliable as compared to news collected through old media news sources and news collected via social media sources is more or less timely as compared to news collected via old media news sources.
The study found that many respondents greatly agreed that social media tools (Facebook, Twitter, YouTube) have become important for following/monitoring news and information; a good number of the respondents agreed that the tools have become an important tool for sharing/recommending news and information; many of them believed that social media tools are to some extent significant for posting or writing both news and information. Several respondents believed that social media tools are neither significant nor insignificant for sharing or recommending information and news. Quite a number of them were of the view that social media tools have become somewhat unimportant for posting/writing news and information. Overall, however, there were a small number of the respondents who agreed that social media tools have become unimportant for following/monitoring/sharing/ recommending/posting/writing news and information. A very strong positive correlation was found between how significant have social media tools become for following or screening news and information and how important have social media tools become for sharing or recommending news and information. In other words, the respondents believed that social media tools have become important for following, monitoring, sharing, and recommending news and information. Equally, a very strong positive correlation between social media tools have become important for following and monitoring news and information and social media tools have become important for posting and writing news and information was found. In other words, only a very small number of the respondents believe that social media tools have not become important for following, monitoring, posting, and writing news and information.

The study found that many of the respondents learned the Egyptian, Tunisian, Libyan and Syrian revolutions via the television. As well, most of the respondents use the radio after learning the Libyan, Tunisian, and Syrian revolutions to spread or share the news. Many of the respondents who stated "Blog" used first learned about the Libyan, Tunisian, and Syrian revolutions via it. Finally, the majority of the respondents used Facebook, Twitter, word-of-mouth, e-mail, mobile device, and other after learning of Egyptian, Libyan, Tunisian, and Syrian revolutions to spread/share the news. A very strong positive correlation was found between learning first about the Egyptian revolution and using newspaper, television, radio, Facebook, Twitter, blog, word-of-mouth, e-mail, mobile device and other to spread this news. In other words, the more the respondents learnt about the Egyptian revolution, the more they used newspaper, television, radio, Facebook, Twitter, blog, word-of-mouth, e-mail, mobile device and other to spread or share the news. Likewise, a very strong positive correlation was found between where the respondents first learnt about Libyan, Tunisian and Syrian revolution and after learning the Libyan, Tunisian, and Syrian they used the following to spread or share this news: newspaper, television, radio, Facebook, Twitter, blog, word-ofmouth, e-mail, mobile device and other. In other words, the more the respondents learnt about the Libyan, Tunisian, and Syrian revolutions, the more they tended to make use of the following to share or spread the news: newspaper, television, radio, Facebook, Twitter, blog, wordof-mouth, e-mail, mobile device and other.

The study found that most respondents use YouTube, Twitter, Facebook, Google News and Wikipedia to follow, share, and post news and information. Some of the social media tools that are not commonly used include StumbleUpon, Associated Content.com, Slashdot, Topix. com and Digg, Link swarm, Craiglist.org, Wunderground, Stirrdup and Shutterstock.com, Plime, Truemors, Linkfilter, and The Onion. com. Those social media tools that are moderately used include Yahoo! News, Other, Blogger, and MySpace. A very weak negative 
correlation was found between using Linkeldln, Yahoo! News, Craiglist.org, MySpace, and Facebook and using Blogger, Propeller, Now Public, Link swarm, and Met filter to share, post and post news and information. In other words, most of the respondents tend to use Linkeldln, Yahoo! News, Craiglist.org, MySpace, and Facebook to follow, share, and post news and information than Blogger, Propeller, Now Public, Link swarm, and Met filter. A weak negative correlation was found between using Topix.com and Bing, Wikipedia, Helium. com, EarthFrisk, and AssociatedContent.com and using Reddit, Slashdot, YouTube, Wunderground, and Stirrdup and Shutterstock. com. Putting it differently, the majority of the respondents use Reddit, Slashdot, YouTube, Wunderground, and Stirrdup and Shutterstock. com. Only a few of them use Topix.com and Bing, Wikipedia, Helium. com, EarthFrisk, and AssociatedContent.com. A strong positive correlation was found between using Truemors, Find Articles, The Onion.com, Linkfilter, and Plime to follow, share, and post news and information and using Stumble Upon, Twitter, News Content, Google News, and Other. In other words, the majority of the respondents use Truemors, Find Articles, The Onion.com, Linkfilter, Plime, Stumble Upon, Twitter, News Content, Google News, and Other to follow, share, and post news and information, though a small number of them tend to use Truemors, Find Articles, The Onion.com, Linkfilter, and Plime than Stumble Upon, Twitter, News Content, Google News, and Other and the other way round.

Finally, the study found out that more respondents use Facebook than blogs to follow, share or post local, international and entertainment news. More respondents use Twitter in following, sharing or posting national news than those who stated they use Facebook; more use Facebook and blogs than Twitter in following, posting or sharing sports, and business and financial news; and, more respondents use blogs in following, sharing or posting weather news than Facebook. Lastly, fewer respondents do not use Twitter to follow/share/post news on blogs as compared to those who use Facebook. A very strong positive correlation was found between respondents' usage of Facebook in following, sharing, or posting various categories of news and their usage of Twitter in following, sharing, or posting various categories of news. In other words, there was a common agreement regarding frequent usage of both Facebook and Twitter in following, sharing, or posting the various categories of news. Similarly, a very strong positive correlation was found between respondents' usage of Facebook in following, sharing, or posting various categories of news and their usage of blogs in following, sharing, or posting various categories of news. Putting it differently, there was a common agreement and/or frequent usage of both Facebook and blogs in following, sharing, or posting the various categories of news, though a small number of the respondents tend to use Facebook more than blogs.

\section{Limitation and Further Directions}

The study concentrated on the use of various social media tools in the United Arab Emirates and their role in Arab Spring in Four other MENA countries, namely, Egypt, Tunisia, Libya and Syria. As a consequence, this study is limited to the five countries. It investigated how social media tools were used during the Arab Spring, and their importance in the United Arab Emirates among 27 interviewees and 454 respondents. It did not represent the entire MENA region. In light of this, the outcomes cannot be generalized. The study can direct Arab media academicians' attention to examine the following: how social media tools were used in other MENA countries such as Yemen and Morocco during the Arab Spring, and whether these tools have vanished media censorship after the revolutions in other Arab countries; if social media is likely to replace old media; frequency of usage of various search tools examined in this study (Google search, Yahoo!, Icerocket, Ask, Bing, Twitter search, StumbleUpon, Technorati, Wikipedia, and News Aggregator). The Arab media scholars should examine the relationship between visiting an old media site subsequent to discovering a news story via social media tool, and visiting a corporate website subsequent to finding out a news story via social media tools in other MENA countries. They should also examine the relationship that exist between using a social media tool to verify information collected via an old media outlet and that between using an old media tool to verify information collected via a social media tool; and, the relationship between using social media tools to verify information collected via a corporate website and using social media tools with the aim of verifying information collected via a press release. Research should also be done in other MENA countries to find out the relationship between the reliability, timeliness, and accuracy of news gathered through social media tools over that gathered through traditional news sources; importance of social media tools in following, monitoring, sharing, recommending, posting, and writing news and information; finally, Arab media scholars can be directed by this study to examine social media tools used in other MENA countries to follow, share and post news. Conducting similar studies in other MENA countries is important since it may lead to different results.

\section{References}

1. Razoux P (2012) Towards a Copernican Revolution in the MENA Region, NATO Defense College, Rome, Italy.

2. Khamis S, Vaughn K (2011) Cyberactivism in the Egyptian Revolution: How Civic Engagement and Citizen Journalism Tilted the Balance. Arab Media \& Society.

3. Kristof N (2009) Tear Down This Cyberwall.

4. Rosaldo R (1981) The Cultural Impact of the Printed Word. Comparative Studies in Society and History 23: 508-513.

5. Hamilton S, Moon D (2012) Twitter, Technology, Transparency, The Struggle To Scale: Keeping Up with the Internet.

6. Andy K (2009) Social Networks: Facebook Takes Over Top Spot, Twitter Climbs.

7. Butler C (2007) The invention of the printing press and its effects.

8. Akesson M (2009) Digital innovation in the value networks of newspapers

9. Haas R (2011) Reflections on the Revolutions in Egypt, The New Arab Revolt New York: The Council on Foreign Relations.

10. Kassem C, Sohail R (2011) The Reasons Social Media Contributed to the 2011 Egyptian Revolution. International Journal of Business Research and Management 3: 139-162.

11. Andreas KM, Haenlein M (2010) Users of the world, unite! The challenges and opportunities of Social Media. Business Horizons 53: 59-68.

12. Sengupta S (2012) Facebook's Prospects May Rest on Trove of Data. The New York Times.

13. Couts A (2012) Facebook now has 901 million monthly active users, 526 million daily users. Digital Trends.

14. Dubai School of Government (2011) Civil Movements: The Impact of Facebook and Twitter.

15. About Twitter (2012) Twitter.

16. YouTube Statistics (2011) YouTube.

17. Alexa (2011) Top Sites.

18. Anhri (2011) Arabic Network for Human Rights Information Online.

19. Laswell $H$ (1948) The structure and function of communication and society: The communication of ideas. New York: Institute for Religious and Social Studies 203-243. 
Citation: Al-Jenaibi B (2012)War and the Worlds and the Promise of Social Media Tools. J Mass Commun Journalism 2:130. doi:10.4172/21657912.1000130

20. Granovetter M (1973) The Strength of Weak Ties. American Journal of Sociology 78: 1360-1380.

21. Katz E, Jay GB, Michael G (2011) Uses and Gratifications Research. The Public Opinion Quarterly 37: 509-523.

22. Wright CR (1960) Functional analysis and mass communication. Public Opinion Quarterly 24: 610-613.

23. McQuail D (1987) Mass Communication Theory (3rdedn).

24. Mattelart A, Mattelart M (1998) Theories of Communication: A Short Introduction. London: Sage Publications.

25. Ryan Y (2011) Tunisia's bitter cyberwar. Al Jazeera.

26. Alexander C (2011) Tunisia's protest wave: where it comes from and what it means, Foreign Policy.

27. Richard S (2011) Tunisia riots: Reform or be overthrown, US tells Arab states amid fresh riots. Telegraph, London, UK.

28. Ayeb H (2011) Social and Political geography of the Tunisian revolution: the Alfa grass revolution. Review of African Political Economy 38: 467-479.

29. Bhoukars A (2011) The Arab Revolutions for Dignity. American Foreign Policy Interests 33: 61-68

30. Freedom house (2012) Tunisia.

31. Afifi O (2011). Tunisian Freedom Day \& our date is January 25.

32. Joshi S (2011) Reflections on the Arab revolutions: Order, democracy and Western policy. The RUSI Journal.

33. Goldstone JA (2011) Understanding the Revolutions of 2011

34. Murphy EC (2011) The Tunisian uprising and the precarious path to democracy. Mediterranean Politics 16: 299-305.

35. Moaddel M (2012) Trends in Values, the Arab Spring, and Implications for National Security Summary.

36. Neil M (2011) Egyptian Voters Approve Constitutional Changes. New York Times

37. Alexander A (2011) Internet role in Egypt's protests. BBC News.

38. Albon CR (2011) 10 must-follow Twitter feeds for Egyptian protests. UN Dispatch.

39. http://www.foreignaffairs.com/articles/67694/jack-a-goldstone/understandingthe-revolutions-of-2011>

40. Beaumont $P$ (2011) The truth about Twitter, Facebook and the uprisings in the Arab world. The Guardian.

41. National Post (2011) Muammar Gaddafi killed as Libyan forces seize Sirte.

42. Siddique H, Owen P, Gabbatt A (2011) Protests in Egypt and unrest in the Middle East-As it happened.

43. Blair D (2011) Yemen's president steps down after 33 years.

44. Lievrouw LA (2011) Alternative and activist new media. Cambridge, MA: Polity Press, UK.

45. Hamdy N (2009) Arab citizen journalism in action: Challenging mainstream media, authorities and media laws. Westminster Papers in Communication and Culture 6: 92-112.

46. Fisher M (2011) Live blogging Egypt: Day 6. The Atlantic.

47. Kirkpatrick DD, Sanger DE (2011) A Tunisian-Egyptian link that shook Arab history. The New York Times.

48. Paciello MA (2011) The Arab Spring: Socio-economic Challenges and Opportunities.

49. Praetorius D (2011) Tweets from the ground in Egypt. The Huffington Post.

50. Saad A, Mohamed O (2011) A virtual "march of millions" in solidarity with Egyptian protesters.

51. Negm N (2011) Tahyees front blog.

52. Essam El-Din G (2011) The coincidental rise and momentous fall of Hosn Mubarak. Ahram online.
53. McAthy R (2011) \#media140-Al Jazeera's early start reporting revolutions.

54. Friedman George (2011) Re-Examining the Arab Spring. Stratfor, USA.

55. Duncombe C (2011) The Twitter Revolution? Social media, representation and crisis in Iran and Libya.

56. Nadia I, Nunns A (2011) Tweets from Tahrir. New York: OR Books.

57. Storck M (2011) The Role of Social Media in Political Mobilisation: a Case Study of the January 2011 Egyptian Uprising.

58. Faris S (2011) Meet the Man Tweeting Egypt's Voices to the World.

59. Egypt's Transition (2011) We Are All Khaled Saeed" Facebook Page.

60. Eltantawy N (2011) Social Media in the Egyptian Revolution: Reconsidering Resource Mobilization Theory. International Journal of Communication 5 : 1207-1224.

61. Hofheinz A (2011) Nextopia? Beyond Revolution 2.0. International Journal of Communication 5: 1417-1434.

62. Mingers J (2001) Combining is research methods: Towards a pluralist methodology. Information Systems Research 12: 240-259.

63. Hammond C (2005) The wider benefits of adult learning: An illustration of the advantages of multi-method research. International Journal of Social Research Methodology 8: 239-255.

64. Tashakkori A, Teddlie C (1998) Mixed methodology: Combining qualitative and quantitative approaches. Thousand Oaks, Sage, USA

65. Plewis I, Mason P (2005) What works and why: Combining quantitative and qualitative approaches in large-scale evaluations. International Journal of Social Research Methodology 8:185-194.

66. Sammons P, Siraj-Blatchford I, Sylva K et al. (2005) Investigating the effects of pre-school provision: Using mixed methods in the eppe research. International Journal of Social Research Methodology 8: 207-224.

67. Hoyles C, Küchemann D, Healy L et al. (2005) Students' developing knowledge in a subject discipline: Insights from combining quantitative and qualitative methods. International Journal of Social Research Methodology 8: 225-238.

68. Sakr N (2007) Approaches to exploring media-politics connections in the Arab world. In Sakr, Naomi, I. B. Taurus, London, UK.

69. Eickelman D, Anderson J (2003) Redefining Muslim Publics. In New Media in the Muslim World: The Emerging Public Sphere. Bloomington: Indiana University Press, USA

70. Stephen A Galak J (2009) The Complementary Roles of Traditional and Socia Media in Driving Marketing Performance. Insead, France. 